Western University Scholarship@Western

1978

\title{
Unanticipated Money, Output, and Prices in the Small Economy
}

W. Michael Cox

Halbert White

Follow this and additional works at: https://ir.lib.uwo.ca/economicsresrpt

Part of the Economics Commons

Citation of this paper:

Cox, W. Michael, Halbert White. "Unanticipated Money, Output, and Prices in the Small Economy." Department of Economics Research Reports, 7827. London, ON: Department of Economics, University of Western Ontario (1978). 
RESEARCH REPORT 7827

UNANTICIPATED MONEY, OUTPUT, AND

PRICES IN THE SMALI ECONOMY

by

W. Michael Cox

and

Halbert White

August, 1978 
UNANTICIPATED MONEY, OUTPUT, AND PRICES IN THE SMALL ECONOMY

by

W. Michael Cox and Halbert White*

The University of Western Ontario

and

University of Rochester

*Department of Economics, University of Western Ontario and University of Rochester. We would like to thank the participants of the Trade-Money workshop at the University of Rochester for their comments on an earlier draft of the paper. Special thanks go to Elhanan Helpman and Ron Jones. 
UNANTICIPATED MONEY, OUTPUT, AND PRICES IN THE SMALL ECONOMY

by

W. Michael Cox and Halbert White

The purpose of this paper is to examine the relationship between output, unanticipated price disturbances, and unanticipated monetary disturbances in the small open economy. The hypothesis that unanticipated price disturbances have real effects follows from the work of Friedman (1968), Lucas (1972, 1973), Sargent and Wallace (1975), and Barro (1976). Lucas (1973) generates a Phillips curve type relationship between employment (output) and unanticipated price disturbances based on the assumption that information is imperfect and expectations are formed rationaliy. The source of this relation is the inability of individuals to discriminate between relative and absolute price disturbances. In this framework, suppliers of labor services, for example, are more likely to respond to an increase in nominal wages if the price level is stable, implying that the slope of the Phillips curve is determined by the variance in the absolute price level relative to the variance in relative prices. The hypothes is that unanticipated monetary disturbances cause movements in employment (with implications for output) was tested by Barro (1977) for the United States. His findings suggest that this relationship is positive with substantial explanatory value.

Although this provides valuable evidence for the case of the United States, the results may not be directly applied to the case of most other economies. This is because the determination of prices in somewhat smaller economies is not completely endogenous to home markets. In addition, the above studies explicitly consider an economy with a single centralized monetary shock, whereas in a 
somewhat smaller economy monetary shocks are likely to be generated from several independent sources. Finally, transactions in each of the economies may be conducted in a separate currency in which case the currency exchange rate regime must be considered.

The primary feature of our study which distinguishes it from the work of Lucas (1972, 1973), Sargent and Wallace (1975), and Barro (1976, 1977) is that the economies considered are small. Smallness is taken to imply that the given economy's contribution to the world demand for and supply of commodities and bonds is insignificant, although clearly the implications may be generalized to apply to any economy wherein the determination of prices is not completely endogenous to home markets. We explicitly consider a small open economy whose monetary shocks have two components--the domestically generated monetary shock and the foreign generated monetary shock. Primary interest is in determining the impact of each of these shocks on the home price level, level of output, and money stock under various exchange rate regimes.

The format of the paper is as follows. Section one presents the formal two-country model (domestic vs. foreign) cast in a monetary framework. The two key assumptions of the setup are that the home country is small and expectations are formed rationally. Section two is devoted to outlining the money supply processes of the two countries. In section three we develop the implications of the model for the home price level, money supply, and level of output under the alternative regimes of a fixed, flexible, and managed exchange rate. This is followed in section four by an examination of the optimal (from the standpoint of monetary autonomy and minimizing the international transmission of disturbances) exchange rate system. Section five focuses on the implications of the model for the exchange rate. In section six we summarize the results. 


\section{Formal Analysis}

The formal setup consists of the following equations:

Domestic Money Demand Function: $\quad M_{t}^{d}=k+P_{t}+a Y_{t}-b i_{t}+\varepsilon_{t}$

Domestic Monetary Equilibrium: $\quad M_{t}^{d}=M_{t}^{s}$

Foreign Money Demand Function: $\quad M_{t}^{* d}=k^{*}+P_{t}^{*}+a Y_{t}^{*}-b_{i}^{*}+\varepsilon_{t}^{*}$

Foreign Monetary Equilibrium: $\quad M_{t}^{* d}=M_{t}^{*} S$

Domestic Output Function:

$$
Y_{t}=\gamma_{t}^{e}+\gamma \tilde{P}_{t}+\epsilon_{t}
$$

Foreign Output Function:

$$
Y_{t}^{*}=Y_{t}^{*} e+\delta \tilde{P}_{t}^{*} \div \varepsilon_{t}^{*}
$$

Purchasing Power Parity

$$
P_{t}=E_{t}+P_{t}^{*}
$$

Interest Parity:

$$
r_{t}=r_{t}^{*}
$$

Fisher Equations:

$$
\begin{aligned}
& i_{t}=r_{t}+\left(P_{t+1}^{e}-P_{t}\right) \\
& i_{t}^{*}=r_{t}^{*}+\left(P_{t+1}^{*}-P_{t}^{*}\right)
\end{aligned}
$$

Determination of Real Rate:

$$
r_{t}^{*}=r_{n}^{*}-k_{t}^{\widetilde{P}}{ }_{t}^{*}+\tau_{t}^{*}
$$

Rational Expectations:

$$
\begin{aligned}
X_{t}^{e} & \equiv E\left[X_{t} \mid I_{t-1}\right] \\
X_{t+j}^{e} & \equiv E\left[X_{t+j} \mid I_{t}\right], j=1, \ldots, \infty
\end{aligned}
$$

Unanticipated Disturbances: $\quad \tilde{x}_{t} \equiv x_{t}-x_{t}^{e}$ 
With the exception of $i_{t}$ and $r_{t}$ all variables are expressed in logarithms. An asterisk denotes the foreign country, $t$ denotes the time period, and the superscripts $d$ and $s$ indicate demand and supply, respectively. A11 random error terms are assumed to be distributed with a zero mean, constant variance, and serial independence. The definitions of the variables are:

$$
\begin{aligned}
M= & \text { the nominal stock of money, } \\
P= & \text { the price level, } \\
Y= & \text { the level of real income, } \\
i= & \text { the nominal interest rate, } \\
r= & \text { the real interest rate, } \\
r_{n}= & \text { the natural real rate of interest, } \\
E= & \text { the exchange rate = the number of units of the home } \\
& \text { currency per unit of the foreign currency, } \\
I_{t}= & \text { information available in time period } t, \\
\varepsilon, \epsilon, \text { and } \tau= & \text { random disturbance terms. }
\end{aligned}
$$

In the analysis that follows, the parameters $a$ and $b$ are assumed to be the same in both countries.

There are a number of important features of this setup. We begin by considering each of these individually. First, the model is cast in an equilibrium setting. Transactions are assumed to take place only at values of the variables which clear all markets.' The specification of each of the above equations depends critically upon this assumption. Were transactions allowed to take place at disequilibrium prices, equations (5) through (11) would be

${ }^{1}$ As indicated by Clower (1965), and Barro and Grossman (1976, chapter 2) the form of demand and supply functions will generally differ in disequilibrium analysis from their counterparts in an equilibrium framework due to the additional set of constraints which the individual faces. Here this is particularly relevant for equations $(1),(3),(5)$, and $(6)$. 
immediately violated as well as the method of forecasting future values of the variables from equilibrium states of the model. Most importantly, however, we would not be able to summarize the workings of the economies through the money demand and monetary equilibrium conditions. Although these considerations provide interesting avenues for possible future research, they are not explored here. All prices are assumed to move instantaneously to clear markets. Furthermore, all transactions involving goods or bonds are assumed to require money. These assumptions allow us via Walras' Law to summarize the net transactions of the goods market and the bond market through the money market. This is the essence of the monetary approach.

A second important feature of the model is that expectations are formed rationally. In short this means that economic agents use all currently available relevant information in forecasting the value of a given variable. This information set specifically includes the structure of the entire economic system as summarized by equations (1) through (14). Equation (12) denotes the forecasts of all current (period $t$ ) variables as based on prior (period $t-1$ ) information, whereas equation (13) defines forecasts of future (period $t+j, j=1, \ldots, \infty$ ) variables as based on current (period $t$ ) information. We follow this convention to avoid carrying the superscripts $e(t)$ and $e(t-1)$ throughout the model. It should be noted that forecasts of period $t+j(j=1, \ldots, \infty)$ variables made in period $t$ bear an additional significance to the extent that these forecasts differ from the forecasts made in period $t-1$. This is because any new information which permits an improved forecast of a variable will in general introduce the potential for profitable use of that information. These forecasting revisions must be accounted for but should be distinguished from the original forecasts since they are unanticipated. We denote the aggregate of these revisions by the term $v_{t}$. 
There are several other features of the model which follow from the use of rational expectations. One of these is the determination of output. We assume that output is independent of the systematic part of the price level but affected by unanticipated changes in prices. ${ }^{2}$ The slope of this Phillips curve relationship corresponds to the coefficients $\gamma$ and $\delta$ in our model. Presumably, the temporary rigidity of labor flows between countries permits each country to have a different Phillips curve slope, although this feature is not crucial to the present study. ${ }^{3}$ For the United States, Barro (1977) has found this relationship to be positive and have considerable explanatory value for unemployment, al though the size of the coefficient cannot be inferred directly since his tests were conducted using unanticipated money rather than unanticipated prices. In our model, the distinction between unanticipated money disturbances and unanticipated price disturbances later becomes crucial for determining the influence of foreign monetary disturbances under various exchange rate regimes.

Notice also that the foreign real rate of interest $\left(r_{t}^{*}\right)$ is assumed to be independent of the systematic part of the foreign price level $\left(P_{t}^{*}\right)$ but affected

20ur particular formulation of equation (5) (and (6)) says that output responds to the unanticipated price variable $\tilde{P}_{t} \equiv P_{t}-E\left[P_{t} \mid I_{t-1}\right]$. This corresponds to Lucas' (1973) formulation of the supply equation. Barro (1976) models $Y_{t}$ as depending on $\left(P_{t}-E\left[P_{t+1} \mid I_{t}\right]\right)$. The problem with this form, for our purposes, is that a simple increase in the rate of inflation (generated, say, by an increase in the money growth rate) will have supply effects. This formulation could be used here if the supply equation were adapted to account for a systematic inflation rate. The properties of this setup, however, are virtualiy identical to those of our formulation, hence we prefer the simpler form of $\widetilde{p}_{t}$. Notice that it has the virtue of extracting out the systematic rate of inflation.

${ }^{3}$ As Ron Jones has pointed out to us, among technological differences and other factors, the presumed information 1 ag between the commodity and labor market in each country is sufficient to invalidate the factor-price equilization theorem in our study, so that each country may have a separate Phillips curve slope. 
by unanticipated changes in foreign prices $\left(\tilde{P}_{t}^{*}\right)$. As pointed out by Sargent (1973), this result can be rationalized along lines similar to the above discussion concerning the effects of unanticipated price disturbances on output. 4 One would expect the sign of this relationship to be opposite that of the relationship between unanticipated price disturbances and output since positive movements in output should reduce the real rate of interest. The magnitude of the coefficient is determined by the magnitude of the Phillips curve slope together with the slope of the aggregate expenditure (IS) curve. Specifically, $\kappa$ equals $\delta / c$ where $c$ represents the interest sensitivity of foreign commodity demand $\left(\Delta Y_{t}^{*} / \Delta r_{t}^{*}\right)$.

Another aspect of our treatment of interest rates concerns the choice of a money demand function. We use the semi-logarithmic money demand form of Cagan (1956). This money demand form is identical to that used in earlier studies of the monetary approach except that it provides a consistent explanation of the demand for money at zero and even negative rates of nominal

${ }^{4}$ For a discussion of this see Sargent (1973, pp. 434-44). The real interest rate equation (11) in our model follows from the foreign country supply equation (6) and a foreign aggregate demand (IS) curve

$$
r_{t}^{*^{d}}=A_{t}^{*^{e}}-c r_{t}^{*}+\epsilon_{t}^{d^{*}}
$$

where $A_{t}^{*^{e}}$ represents systematic demand and $\epsilon_{t}^{d^{*}}$ represents the random component of aggregate foreign demand. The home country commodity demand and supply equations have been omitted by the assumption of home country smallness. Equating $Y_{t}^{*^{d}}$ to $Y_{t}^{* S}$ (which equals $Y_{t}^{*}$ ) and solving for $r_{t}^{*}$ gives

$$
r_{t}^{*}=\left(A_{t}^{*^{e}}-Y_{t}^{*^{e}}\right) / c-(\delta / c) \tilde{P}_{t}^{*}+\left(\epsilon_{t}^{*}-\epsilon_{t}^{d^{*}}\right) / c \text {. }
$$

Hence $\left(A_{t}^{*^{e}}-Y_{t}^{*^{e}}\right) / c$ corresponds to $r_{n}^{*}, \delta / c$ corresponds to $k$, and $\left(\epsilon_{t}^{*} t_{t}^{d^{*}}\right) / c$ corresponds to $\tau_{t}^{*}$ in (11). For simplicity, we assume that systematic demand $\left(A_{t}^{*}\right)$ grows at the same rate as systematic supply $\left(Y_{t}^{*^{e}}\right)$ so that the natural part of the real rate of interest remains constant over time. Notice also that $k$ is directly related to the slope of the foreign aggregate expenditure curve $(1 / \mathrm{c})$, and foreign Phillips curve slope $(\hat{c})$. 
interest. The primary advantage of this money demand form, however, is that it allows for a separation of the nominal interest rate into its real and inflationary components, thereby permitting forecasts of future rates of inflation to be generated within the model. Sargent and Wallace (1973) have successfully applied this money demand function (the real component of the interest rate was omitted in their study) in the context of a rational expectations model to test the hyperinflationary periods of Germany, Austria, and several other European countries. 5 Bilson (1977a) presents a monetary model of exchange rates using the semi-logarithmic money demand form with rational expectations, and later (1977b) successfully applies the model to the 1971-1975 experience of the United Kingdom.

Throughout the study we use the variables $M_{t}^{e}$ and $Y_{t}^{e}$ to denote the systematic part of current money and income, respectively. Unanticipated movements in money $\left(\tilde{M}_{t}\right)$ and income $\left(\tilde{Y}_{t}\right)$ are constructed such that they are orthogonal to $M_{t}^{e}$ and $Y_{t}^{e}$, based on period $t-1$ information. We follow this procedure to preserve the generality of the results.

The final feature of the model which should be noted is the particular use of the monetary approach. Since we are interested in discriminating the impact of domestic vis-à-vis foreign monetary policies, we treat the foreign country as the rest-of-the-world throughout the study. In addition, the home country is assumed to be small enough so that for all practical purposes the foreign price level and real interest rate are determined by the foreign economy and given exogenously to the home country.

\section{Specification of the Monetary Processes}

The final task that remains before we can evaluate the implications of the model is a specification of the monetary processes for the home and foreign

${ }^{5}$ For related work see also Bailey (1956), and Barro (1970). 
economy. By definition

$$
\begin{aligned}
& M_{t} \equiv m+H_{t}, \text { and } \\
& M_{t}^{*} \equiv m^{*}+H_{t}^{*},
\end{aligned}
$$

where $H$ represents (the $\log$ of) high-powered money and $m$ represents the (log of the) money multiplier. High-powered money consists of international reserves $(R)$ and domestic credit $(D)$. The variable $D$ represents the domestic monetary policy variable of the home economy and $D *$ represents that variable for the foreign economy. In the case we are considering, the size of the foreign economy implies that its high-powered money measures, for all practical purposes, the level of domestic credit, so that we may replace $H_{t}^{*}$ by $D_{t}^{*}$ in equation (16). It follows from our definition of unanticipated monetary disturbances that $\tilde{M}_{t}^{\star}$ equals $\tilde{D}_{t}^{\star}$. This equivalence later becomes convenient in the presentation of the reduced form equations.

For the home central bank we postulate a money supply function of the form

$$
M_{t}=\beta+m+D_{t}-v\left[E_{t}-E_{0}\right]
$$

The parameters $\beta$ and $\nu$ as well as the target exchange rate $\left(E_{0}\right)$ and level of domestic credit $\left(D_{t}\right)$ are determined by the central bank of the home country. By selecting a value for $\beta$, given $\nu, E_{0}$, and $E_{t}$, the home monetary authorities can control the composition of high-powered money between international reserves and domestic credit. By choice of the magnitude of $v$ the central bank can determine the degree to which it supports the target exchange rate 
through its purchases and sales of international reserves, In general, $v>0$ describes a policy of managing the exchange rate via intervention in the foreign exchange market, which we term a managed float. It should be pointed out that intervention is effective only to the extent international reserve movements are allowed to affect the money supply and thereby the price level of the home country. This follows from the assumptions of home country smallness and purchasing power parity. Sterilization operations are not effective and therefore are not considered here.

This money supply function is general enough to characterize a policy of fixing the exchange rate or allowing the exchange rate to float freely. As $\nu \rightarrow \infty, M_{t}$ becomes strongly responsive to deviations of $E_{t}$ from $E_{0}$, implying a home central bank policy of fixing the exchange rate. $v=0$ describes a situation where the home central bank's monetary policy is independent of movements in the exchange rate, thus describing a system of freely floating (flexible) exchange rates.

\section{Implications of the Model}

Equations (1) - (17) summarize the system which we are interested in solving for the values of $P_{t}^{*}, P_{t}, Y_{t}, M_{t}$, and $E_{t}$. Since the derivation of each of these is quite lengthy only the reduced form expressions will be presented here. We invite the reader to consult the appendix for working through the model.

Since the home country is assumed to be small vis-à-vis the foreign country, $P_{t}^{*}$ may be determined independently of equations $(1),(2),(5),(7),(8),(9)$, and (17). By equating $M_{t}^{* d}$ and $M_{t}^{*^{S}}$ after making the appropriate substitutions from $(3),(6),(10),(11)$, and (16), the foreign price level may be determined as

$$
P_{t}^{*}=\pi_{1}+\pi_{2} \sum_{j=1}^{\infty} \theta^{j} D_{t+j-1}^{*}-\pi_{3} \sum_{j=1}^{\infty} \theta^{j} Y_{t+j-1}^{\star} e^{e}+\pi_{4} \tilde{D}_{t}^{\star}+V_{t}^{\star}+e_{t}^{\star}
$$




$$
\text { where } \begin{aligned}
\pi_{1} & =b r_{n}^{*}+m^{*}-k^{*}, \\
\pi_{2} & =1 / b, \\
\pi_{3} & =a / b=a \pi_{2}, \\
\pi_{4} & =\eta=1 /(1+a \delta+b(k+1)), \text { and } \\
\theta & =b /(1+b) .
\end{aligned}
$$

The expression for each of the reduced form random error terms $\left(e_{t}\right)$ and forecasting revision terms $\left(V_{t}\right)$ is given in the appendix.

Equation (18) says that this period's (period t's) foreign price level is determined partially by last period's forecast of this period's foreign money variable $\left(\mathrm{O}_{\mathrm{t}}^{\star^{\mathrm{e}}}\right)$ and foreign real income level $\left(\mathrm{Y}_{\mathrm{t}}^{*^{\mathrm{e}}}\right)$, and partially by this period's forecasts of the future values of those variables $\left(D_{t+j}^{*}\right.$ and $\left.\gamma_{t+j}^{* e}\right)$. In addition, the error in the forecast of this period's foreign monetary policy--the unanticipated monetary disturbance--causes movements in $P_{t}^{*}$. A similar result nolds for each component of the $e_{t}^{*}$ term, as well as those of the $V_{t}^{*}$ expression.

As equation (18) makes clear, the systematic part of the foreign price level is determined by the systematic parts of foreign real income and domestic credit. We may determine the source of unanticipated movements in the foreign price level by taking expectations of both sides of equation (18) conditioned on the information available at time period $t-1$, then subtracting this result from both sides of (18). This gives

$$
\tilde{P}_{t}^{\star}=\pi_{5} \tilde{D}_{t}^{*}+V_{t}^{*}+e_{t}^{*}
$$

where $\pi_{5}=1 /(1+a \delta+b(\kappa+1))=n=\pi_{4}$, 
A one percentage point $\tilde{D}_{t}^{\star}$ does not imply a full one percentage point $\tilde{P}_{t}^{\star}$ since the unanticipated price disturbances call forth (i) movements in output (hence the term $a \delta$ in the $n$ expression), ( $i i)$ movements in the inflationary component of the nominal interest rate (hence the term b), and ( $i i i$ ) movements in the real rate of interest (hence the term bK). Each of these causes a movement of $M_{t}^{*^{d}}$ toward $M_{t}^{*^{S}}$ which precludes a unit impact on $\tilde{P}_{t}^{\star}$. The term $n$ is used throughout the model to summarize the net impact of $\tilde{D}_{t}^{\star}$ on $\tilde{P}_{t}^{*}$.

Since $e_{t}^{*}$ is assumed to be random we are not interested in focusing on its implications for the model. As for $V_{t}^{\star}$, to the extent new information is gained between period $t-l$ and period $t$ which allows improved forecasts of the policy variable $D_{t+j}^{\star}$, the results are not uninteresting. However, revisions in the forecast of $D_{t+j}^{*}$ cause unanticipated price disturbances much in the same way as unanticipated current monetary disturbances. For this reason we focus on the impact of the unanticipated current monetary disturbances. 6

The determination of $P_{t}$ requires each equation of the model. One reason is because the money stock of the home country is affected by movements in the

${ }^{6}$ Several special cases of revisions should perhaps be considered. If the monetary authorities of the foreign economy are following a policy which allows unanticipated disturbances in the level of domestic credit to accumulate over time, then $\widetilde{\delta}_{t-1}^{*}$ will be incorporated into $D_{t+j}^{e}, j=1, \ldots, \infty$. In this case an unanticipated monetary expansion has effects which linger into the next period. These effects come in the form of revisions in the forecast of $D_{t+j}^{*}$. Current unanticipated money disturbances may also have effects on output which persist into the future. In this case a $\tilde{D}_{t-1}^{\star}$ affects $Y_{t+j}^{\star e}$ and thereby. $V_{t}^{\star}$. From the expression for $V_{t}^{*}$ (given in the appendix) it is clear that persistence effects tend to reduce the unanticipated price disturbances in the immediately following period since then $\tilde{D}_{t-1}^{\star}$ generate opposite $v_{t}$. Finally if the foreign monetary authorities announce $D_{t+j}^{*}$ which, in general, differ from $E\left[D_{t+j}^{*} \mid I_{t-1}\right]$, $(j=1, \ldots, \infty)$, then to the extent these announcements are believed, some revision in the forecast of $D_{t+j}^{*}$ is called for. 
exchange rate, and the exchange rate is determined by both $P_{t}$ and $P_{t}^{*}$. However, even if the home authorities follow a monetary policy which is independent of the foreign economy, as represented by setting $v=0$ (flexible exchange rates), $P_{t}$ is still partially dependent upon the foreign economy through the influence of $r_{t}^{*}$. The reduced form expression for the home price level is, in general

$$
\begin{aligned}
P_{t}=\pi_{6} & +\pi_{7} \sum_{j=1}^{\infty} \omega^{j} D_{t+j-1}^{e}-\pi_{8} \sum_{j=1}^{\infty} \omega^{j} Y_{t+j-1}^{e}+\pi_{9} \sum_{j=1}^{\infty}\left(\theta^{j}-\omega^{j}\right) D_{t+j-1}^{e^{e}} \\
& -\pi_{10} \sum_{j=1}^{\infty}\left(\theta^{j}-\omega^{j}\right) Y_{t+j-1}^{\star}{ }_{t+1}^{e}+\pi_{11} \tilde{D}_{t}+\pi_{12} \tilde{D}_{t}^{*}+v_{t, 1}+e_{t, 1}
\end{aligned}
$$

where $\quad \pi_{6}=b r_{n}^{*}+\left[m+v m^{*}-k-v k^{*}+v E_{0}+\beta\right] /(1+v)$

$$
\begin{aligned}
\pi_{7} & =\pi_{9}=1 / b=\pi_{2}, \\
\pi_{8} & =\pi_{10}=a / b=\pi_{3}, \\
\pi_{11} & =1 /(1+a \gamma+b+v), \\
\pi_{12} & =n(\nu-b k) /(1+a \gamma+b+v)=\pi_{11} \pi_{4}(v-b k), \\
\omega & =b /(1+b+v) .
\end{aligned}
$$

The home price level is determined partially by the home money and income variables and partially by the foreign money and income variables. ${ }^{7}$

Notice that as $v$ becomes large, $\omega$ becomes small implying that the determination of $P_{t}$ shifts toward the foreign money and income variables and away from the home factors. In the extreme case of fixed exchange rates $(v+\infty), \omega=0$ as does the coefficient on the unanticipated domestic credit disturbance $\left(\pi_{11}\right)$

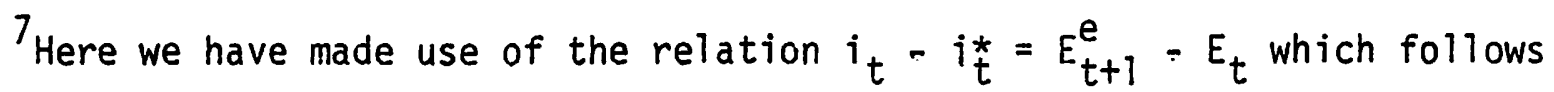
from equations (7), (8), (9), and (10) and the hypothesis of rational expectations. 
implying that the home price level is completely controlled by the foreign economy. In the opposite case of perfectly flexible exchange rates $(v=0), \theta$ equals $\omega$ implying that the systematic foreign money and income factors leave $P_{t}$ unaffected. However, unanticipated foreign monetary disturbances retain some effect on home prices, as evidenced by the fact that $\pi_{12}$ equals $-b_{k n} \pi_{11}$. This is because unanticipated foreign monetary disturbances cause unanticipated foreign price disturbances which affect the real rate of interest, home money demand and thereby the home price level. The implications of this are investigated in more detail in section four.

The factors causing unanticipated movements in the home price level may be singled out by taking expectations of both sides of equation (20) conditioned on the information available at time period $t-1$, and subtracting the result from both sides of $(20)$. This yields

$$
\tilde{P}_{t}=\pi_{13} \tilde{D}_{t}+\pi_{14} \tilde{D}_{t}^{\star}+v_{t, 1}+e_{t, 1}
$$

$$
\text { where } \begin{aligned}
\pi_{13} & =1 /(1+a \gamma+b+v)=\pi_{11}, \\
\pi_{14} & =n(\nu-b k) /(1+a \gamma+b+v)=\pi_{12} .
\end{aligned}
$$

Notice that if the central bank of the home country wishes to maintain a policy of fixed exchange rates $(v+\infty)$, they must forfeit their ability to influence (even temporarily) the domestic price level $\left(\pi_{13}+0\right)$. Any unanticipated shocks in the home monetary policy variable will be completely absorbed by the foreign economy under a system of fixed rates.

We may now examine the implications of this setup for the level of home output, home money supply, and the exchange rate. Substituting into equation (5) for $\tilde{\mathrm{P}}_{t}$ gives 


$$
Y_{t}=Y_{t}^{e}+\pi_{15} \tilde{D}_{t}+\pi_{16} \tilde{D}_{t}^{*}+V_{t, 2}+e_{t, 2}
$$

where $\pi_{15}=\gamma /(1+a \gamma+b+v)=\gamma \pi_{11}$, and

$$
\pi_{16}=m(v-b k) /(1+a \gamma+b+v)=\gamma \pi_{12} .
$$

The level of home output is the systematic part $\left(Y_{t}^{e}\right)$ plus or minus an amount which depends on the unanticipated home and foreign monetary disturbances.

The factors determining the exchange rate may be identified by substituting into equation (7) for $P_{t}^{*}$ and $P_{t}$. The result is

$$
E_{t}=\pi_{17}+\pi_{18} \sum_{j=1}^{\infty} \omega^{j} \tilde{D}_{t+j-1}^{e}-\pi_{19} \sum_{j=1}^{\infty} \omega^{j} \gamma_{t+j-1}^{e}+\pi_{20} \tilde{D}_{t}-\pi_{21} \tilde{D}_{t}^{t}+v_{t, 3}+e_{t, 3}
$$

where $\pi_{17}=\left(m-m^{*}-k+k^{*}+\beta+\nu E_{0}\right) /(1+\nu)$,

$$
\begin{aligned}
\pi_{18} & =1 / b=\pi_{2}, \\
\pi_{19} & =a / b=\pi_{3}, \\
\pi_{20} & =1 /(1+a \gamma+b+v)=\pi_{11}, \\
\pi_{21} & =(1+a n(\gamma-\delta)) /(1+a \gamma+b+\nu)=\pi_{11}\left[1+a \pi_{4}(\gamma-\delta)\right], \\
\bar{D} & =D-D^{*}, \\
\bar{Y} & =Y-Y^{*} .
\end{aligned}
$$

The systematic part of the exchange rate is determined by the relative systematic parts of money $(\bar{D})$ and income $(\bar{Y})$ for the two countries. Unanticipated monetary disturbances cause unanticipated movements in the exchange rate. It is clear that this result also applies to the case where the home central bank is 
allowing the exchange rate to float freely $(\nu=0)$. In the case of fixed exchange rates, of course, neither the systematic nor unanticipated factors affect the exchange rate. This may be verified by letting $v \rightarrow \infty$ in equation (23) and observing that each part of the above expression falls out except the target exchange rate $E_{0}$.

Finally, we may identify the factors determining the home money supply by substituting into equation (17) for $E_{t}$. This gives

$$
\begin{aligned}
M_{t}=\pi_{22}+\pi_{23} D_{t}^{e}+\pi_{24} D_{t}^{* e} & +\pi_{25} \sum_{j=2}^{\infty} \omega^{j} \widetilde{D}_{t+j-1}^{e}-\pi_{26} \sum_{j=1}^{\infty} \omega^{j} \bar{Y}_{t+j-1}^{e} \\
& +\pi_{27} \tilde{D}_{t}+\pi_{28} \tilde{D}_{t}^{\star}+v_{t, 4}+e_{t, 4},
\end{aligned}
$$

where $\pi_{22}=\left[v m^{*}+m+v E_{0}-v k^{*}+v k+\beta\right] /(1+v)$,

$$
\begin{aligned}
& \pi_{23}=1-v \omega / b=1-\pi_{2} v \omega, \\
& \pi_{24}=v \omega / b=\pi_{2} v \omega, \\
& \pi_{25}=v / b, \\
& \pi_{26}=a v / b=\pi_{3} v, \\
& \pi_{27}=(1+a \gamma+b) /(1+a \gamma+b+v)=1-v \pi_{11}, \\
& \pi_{28}=v(1+a n(\gamma-\delta)) /(1+a \gamma+b+v)=v \pi_{21} .
\end{aligned}
$$

The money stock of the home country is determined by the systematic relative income levels $\left(\bar{Y}_{t+j}^{e}\right)$, systematic relative levels of domestic credit $\left(\bar{D}_{t+j}^{e}\right)$, and the current unanticipated home $\left(\tilde{D}_{t}\right)$ and foreign $\left(\tilde{D}_{t}^{*}\right)$ generated monetary disturbances. An unanticipated home credit disturbance causes a less than proportionate increase in the home money supply since the home central bank must sell reserves to support the exchange rate. Similarly, a positive $\tilde{D}_{t}^{\star}$ 
implies an increase in $M_{t}$ since the home authorities must purchase an additional amount of the foreign currency,

This completes the derivation of the reduced form equations for the general case of a managed float. The case of fixed exchange rates may be inferred by allowing v>o in equations (22), (23), and (24), and that for flexible rates by setting $v=0$. For ease of reference we present these reduced form $P_{t}, Y_{t}$, $M_{t}$, and $E_{t}$ equations below. To further facilitate a comparison of the alternative exchange rate regimes we also summarize the coefficients on the unanticipated home $\left(\tilde{D}_{t}\right)$ and foreign $\left(\tilde{D}_{t}^{\star}\right)$ money disturbances in Tables I and II. ${ }^{8}$

Consider first the case of fixed exchange rates. As Table 1 points out, an unanticipated home money issue has no effect on the home price level, money suppiy, or level of output under fixed exchange rates. On the other hand foreign monetary disturbances have full impact on $P_{t}, M_{t}$, and $Y_{t}$ under fixed rates. An unanticipated foreign money issue causes an increase in foreign prices and an equiproportionate increase in home prices. The increase in home prices increases the home demand for money thereby requiring the home central bank to buy international reserves in order to avoid an increase in $P_{t}^{*}$ relative to $P_{t}$, that is to avoid an appreciation of the exchange rate. The home money supply increases equiproportionately to the increase in the foreign money supply, plus or minus an amount which depends on the comparative slopes of the home and foreign Phillips curves. $\gamma>\delta$ requires a more than proportionate increase in the home money stock since $\tilde{P}_{t}^{\star}$ (which equals $\tilde{P}_{t}$ in this case) raises the home level of output,

${ }^{8}$ Clearly, the specification of the home money supply equation (17) is not critical to the reduced form $P_{t}, Y_{t}, M_{t}$, and $E_{t}$ equations for the boundary cases of fixed and flexible exchange rates. This is because in (17) $M_{t}$ is linearly related to $D_{t}$. The case of fixed exchange rates could then alternatively be derived by setting $E_{t}=E_{0}$ and replacing $\tilde{D}_{t}$ with $\tilde{M}_{t}$ wherever it appears. For the case of flexible rates, $\beta+m+D_{t}$ could simply be replaced by $M_{t}$, and $\tilde{D}_{t}$ by $\tilde{M}_{t}$. 


\section{FIXED EXCHANGE RATES}

$$
\begin{aligned}
& P_{t}=\pi_{29}+\pi_{30} \sum_{j=1}^{\infty} \theta^{j} D_{t+j-1}^{\star} e_{31} \sum_{j=1}^{\infty} \theta^{j}{ }_{t+j-1}^{\star} e^{e}-\pi_{32} \tilde{D}_{t}^{\star}+V_{t, 5}+e_{t, 5} \\
& Y_{t}=Y_{t}^{e}-\pi_{33} \tilde{D}_{t}^{*}+v_{t, 6}+e_{t, 6} \\
& M_{t}=\pi_{34}+\pi_{35} D_{t}^{* e}+\pi_{36} \bar{Y}_{t}^{e}+\pi_{37} \widetilde{D}_{t}^{\star}+V_{t, 7}+e_{t, 7} \\
& E_{t}=E_{0}
\end{aligned}
$$

\section{FLEXIBLE EXCHANGE RATES}

$$
\begin{aligned}
& P_{t}=\pi_{38}+\pi_{39} \sum_{j=1}^{\infty} \theta^{j} D_{t+j-1}^{e}-\pi_{40} \sum_{j=1}^{\infty} \theta^{j} Y_{t+j-1}^{e}+\pi_{41} \tilde{D}_{t}-\pi_{42} \tilde{D}_{t}^{\star}+v_{t, 8}+e_{t, 8} \\
& Y_{t}=Y_{t}^{e}+\pi_{43} \widetilde{D}_{t}-\pi_{44} \tilde{D}_{t}^{\star}+v_{t, 9}+e_{t, 9} \\
& M_{t}=\pi_{45}+\pi_{46} D_{t}^{e}+\pi_{47} \tilde{D}_{t} \\
& E_{t}=\pi_{48}+\pi_{49} \sum_{j=1}^{\infty} \theta^{j} \bar{D}_{t+j-1}^{e}-\pi_{50} \sum_{j=1}^{\infty} \theta^{j} \bar{Y}_{t+j-1}^{e}+\pi_{51} \widetilde{D}_{t}-\pi_{52} \tilde{D}_{t}^{\star}+v_{t, 10}+e_{t, 10}
\end{aligned}
$$

where

$$
\begin{aligned}
\pi_{29} & =b r_{n}^{*}+m^{*}-k^{*}+E_{0}, & \pi_{41} & =1 /(1+a \gamma+b), \\
\pi_{30} & =1 / b, & \pi_{42} & =n b k /(1+a \gamma+b), \\
\pi_{31} & =a / b, & \pi_{43} & =\gamma /(1+a \gamma+b), \\
\pi_{32} & =n, & \pi_{44} & =n \gamma b k /(1+a \gamma+b), \\
\pi_{33} & =m, & \pi_{45} & =m+\beta, \\
\pi_{34} & =E_{0}+k-k^{*}+m^{*} & \pi_{46} & =1, \\
\pi_{35} & =1, & \pi_{47} & =1, \\
\pi_{36} & =a, & \pi_{48} & =m-m^{*}-k+k^{*}+\beta, \\
\pi_{37} & =1+a n(\gamma-\delta), & \pi_{49} & =1 / b, \\
\pi_{38} & =b r_{n}^{*}+m-k+\beta & \pi_{50} & =a / b, \\
\pi_{39} & =1 / b, & \pi_{51} & =1 /(1+a \gamma+b), \text { and } \\
\pi_{40} & =a / b, & \pi_{52} & =[1+a n(\gamma-\delta)] /(1+a \gamma+b) .
\end{aligned}
$$


TABLE I: Coefficients on $\tilde{\mathrm{D}}_{t}$

\begin{tabular}{|c|c|c|c|}
\hline \multirow{2}{*}{ Equation } & \multicolumn{3}{|c|}{ EXCHANGE RATE REGIME } \\
\cline { 2 - 4 } & Fixed & Managed & Flexible \\
\hline$P_{t}$ & 0 & $\frac{1}{1+a \gamma+b+\nu}$ & $\frac{1}{1+a \gamma+b}$ \\
\hline$Y_{t}$ & 0 & $\frac{\gamma}{1+a \gamma+b+\nu}$ & $\frac{\gamma}{1+a \gamma+b}$ \\
\hline$M_{t}$ & 0 & $\frac{1+a \gamma+b}{1+a \gamma+b+v}$ & 1 \\
\hline$E_{t}$ & 0 & $\frac{1}{1+a \gamma+b+\nu}$ & $\frac{1}{1+a \gamma+b}$ \\
\hline
\end{tabular}

TABLE II: Coefficients on $\widetilde{\mathrm{D}}_{t}^{*}$

\begin{tabular}{|c|c|c|c|}
\hline \multirow{2}{*}{ Equation } & \multicolumn{3}{|c|}{ EXCHANGE RATE REGIME } \\
\cline { 2 - 4 } & Fixed & Managed & Flexible \\
\hline$P_{t}$ & $n$ & $\frac{n(\nu-b \kappa)}{1+a \gamma+b+v}$ & $\frac{-n b k}{1+a \gamma+b}$ \\
\hline$Y_{t}$ & $m$ & $\frac{\gamma n(\nu-b \kappa)}{1+a \gamma+b+v}$ & $\frac{-\gamma n b k}{1+a \gamma+b}$ \\
\hline$M_{t}$ & $1+a n(\gamma-\delta)$ & $\frac{v[1+a n(\gamma-\delta)]}{1+a \gamma+b+v}$ & 0 \\
\hline$E_{t}$ & 0 & $-\frac{1+a n(\gamma-\delta)}{1+a \gamma+b+\nu}$ & $-\frac{1+a n(\gamma-\delta)}{1+a \gamma+b}$ \\
\hline
\end{tabular}

thereby causing an increase in the demand for money in the home country relative to the foreign country. The precise effect of $\tilde{D}_{t}^{\star}$ on $Y_{t}$ is governed by the slope of the home Phillips curve $(\gamma)$ and the parameter $n$ which equals $1 /(1+a \delta+b(k+1))$. Most of the foreign monetary shock is absorbed by the foreign economy when the foreign economy's Phillips curve slope $(\delta)$ is large. On the other hand, when $\delta$ is small and $\gamma$ is large foreign monetary disturbances are heavily transmitted to the home country's level of output under fixed rates. 
Under a home central bank policy of flexible exchange rates the home money supply is independent of unanticipated (or anticipated) foreign monetary disturbances. This follows from the definition of freely floating exchange rates. However, the monetary independence does not imply output independence since $\tilde{D}_{t}^{*}$ causes a movement if $r_{t}^{*}$ and a corresponding movement in $r_{t}$. The movement in $r_{t}$ in turn affects the home level of money demand, causing an unanticipated movement in the home price level and thereby home output.

\section{A Comparison of Alternative Exchange Rate Systems}

The purpose of this section is to investigate the implications of the model for monetary autonomy and for the international transmission of disturbances. It has become somewhat conventional lately to associate these two aspects with the optimality of alternative exchange rate systems.

As Table II indicates, there are two channels whereby unanticipated foreign monetary disturbances affect the home economy. The first of these is through money flows (represented by the term $v$ ) and the second is through movements in the real rate of interest (represented by $k$ ). Under fixed exchange rates the money flows dominate since the condition of purchasing power parity must be maintained. An unanticipated domestic credit disturbance by the foreign central bank implies an incipient excess supply of money and a depreciation in the foreign currency. To prevent the foreign currency from depreciating, the home country must buy an equivalent amount of international reserves at the fixed rate $E_{0}$. Hence the mechanism which allows $\tilde{D}_{t}^{\star}$ to affect $\tilde{P}_{t}$ and thereby $Y_{t}$ is the balance of payments.

Under flexible rates this channel of influence is closed and the real interest rate effect dominates. Since a downward sloping aggregate foreign expenditure (IS) curve implies $\kappa / \delta>0$, the effect of $\widetilde{\delta}_{t}^{\star}$ on $Y_{t}$ under flexible rates must always be opposite in sign to that of fixed rates. Assuming that 
$\hat{\delta}>0$, it must be that $\kappa>0$ so that a one percentage point $\tilde{D}_{t}^{*}$ causes a net increase in $Y_{t}$ of $\gamma$ under fixed exchange rates but a net decrease in $Y_{t}$ of $m b k /(1+a \gamma+b)$ under flexible rates. More interestingly, given a sufficiently steep foreign aggregate expenditure curve, the effect of $\tilde{D}_{t}^{\star}$ on $Y_{t}$ can be stronger under flexible rates than under fixed rates. This result is particularly important since it is commonly believed that to the extent monetary disturbances are transmitted across countries under flexible rates, they simply yield a damped (by the exchange rate) equivalent of the effects generated under fixed exchange rates. The relevant comparison is clearly

$$
\frac{\delta}{c} \geq \frac{1+a \gamma+b}{b} \text {. }
$$

Hence a low interest sensitivity of foreign commodity demand (c) favors a heavier transmission of unanticipated foreign money disturbances to the home level of output under flexible rates than under fixed rates.

It is also clear that the slope of the home $(\gamma)$ and foreign $(\delta)$ Phillips curves, the income elasticity of money demand (a), and the interest sensitivity of money demand (b) play a major role in this question. Specifically, a gradually sloped foreign Phillips curve, a low income elasticity of money demand, and a high interest sensitivity of money demand favor a greater effect of $\tilde{D}_{t}^{\star}$ on $Y_{t}$ under flexible rates than under fixed rates. ${ }^{9}$ In addition, a steeply sloped (excepting

${ }^{9}$ This point may be made more relevant by postulating some reasonable values for the parameters $a, b, \delta$, and $\gamma$. Bailey (1956) has estimated the semi-logarithmic money demand form for the hyper-inflationary periods of several European economies. His estimates suggest an average value for b of approximately 5.11 . Lucas (1973) has estimated the output-inflation tradeoff for a number of economies. His estimates of the Phillips curve slope range from a maximum of 10.11 (for the United States) to a minimum of .40 (Sweden). The average $\gamma$-value for fourteen economies (excepting the United States, Argentina, Puerto Rico, and Paraguay) is 1.73. If we let the U.S. value of 10,11 represent the foreign Phillips curve slope $(\delta)$ and postulate a unitary income elasticity of money demand, this yields a critical value for $\Delta Y / \Delta r$ of approximately 6.61 which is not unreasonable. We are currently attempting to test the hypotheses of our study for several small economies over their respective fixed exchange rate periods. 
vertical) home Phillips curve favors a relatively greater transmission of foreign disturbances to the home level of output under flexible rates. ${ }^{10}$ Each of these factors favors a stronger impact of $\tilde{D}_{t}^{\star}$ on $r_{t}^{*}$, hence a stronger impact of $\tilde{D}_{t}^{\star}$ on $M_{t}^{d}$, and thereby onto $P_{t}$.

Regardless of the particular magnitudes of $a, b, c, \gamma$, and $\delta$, it is clear that unanticipated foreign monetary disturbances are transmitted to the home price level and home level of output under both fixed and flexible exchange rates. It is important to note, however, that because (i) fixed and flexible rates represent boundary cases of the general case of a managed float, and because (ii) the sign of effect of $\tilde{D}_{t}^{\star}$ on $P_{t}$ under fixed rates is opposite that of flexible rates, there must be some intermediate degree of intervention for which $P_{t}$ is independent of $\tilde{D}_{t}^{\star}$. As Table II indicates, this degree of intervention is precisely $v=b k$, since then the coefficient on $\tilde{D}_{t}^{\star}$, given as $n(v-b k) /(1+a \gamma+b+v)$, equals zero. The rationale for this is straightforward. An unanticipated foreign money expansion lowers the real rate of interest and thereby increases the demand for money in the home country (as represented by the term bK). If the home monetary authorities allow an equal increase in the home money supply via the balance of payments (set $\nu=b_{k}$ ), then no home price disturbance will be required to clear the home money market.

The central point is that the "dirty" float (perhaps inappropriately termed) is the only exchange rate regime which insulates the home economy from unanticipated foreign monetary disturbances, thereby allowing the home authorities monetary autonomy. However, at least two other considerations are relevant here. The first of these concerns the ability of the home monetary authorities to influence the home economy through $\widetilde{D}_{t}$. As Table I indicates, the coefficient on $\widetilde{D}_{t}$ in the

10 of course foreign monetary disturbances are, in general, transmitted more heavily to $Y_{t}$ when the slope of the home Phillips curve $(\gamma)$ is large. 
$P_{t}, M_{t}$, and $Y_{t}$ equations reaches $i$ ts maximum value when $v$ equals zero. The home monetary authorities have maximum influence over the home economy under flexible exchange rates. Although a managed float (specifically $v=b k$ ) permits the authorities their desired monetary autonomy, it in turn reduces their ability to influence the home economy through $\tilde{D}_{t}$. Notice that setting $\nu$ equal to bK implies that the coefficient on $\tilde{D}_{t}$ in the $P_{t}$ equation becomes $1 /(1+a \gamma+b(k+1)) .11$ This indicates that the factors which favor a higher transmission of $\tilde{D}_{t}^{*}$ to $Y_{t}$ under flexible rates also act to reduce the impact of $\tilde{D}_{t}$ on $Y_{t}$ under a managed float. A gradually sloped foreign Phillips curve, a steeply sloped foreign expenditure curve, and a high interest sensitivity of money demand all sharply limit the ability of the home monetary authorities to influence the home economy under a managed rate policy.

The second relevant consideration concerns the systematic foreign money and income variables. Under flexible exchange rates the systematic foreign money and income variables leave the home economy unaffected. However, the influence of $\tilde{D}_{t}^{\star}$ remains. If the home central bank follows a managed rate policy (specifically $\left.v=b_{k}\right)$ the influence of $\tilde{D}_{t}^{\star}$ is eliminated but the influence of systematic foreign money and income variables is introduced. This is particularly important if the foreign authorities are following a systematic monetary policy which results in substantial price inflation. The implication then is that the home monetary authorities must import systematic foreign inflation in order to insulate their economy from the unanticipated foreign money disturbances. Once again, this problem is intensified if the parameters $\delta, b$, and $1 / c$ are large.

It would be easy to postulate an aggregate home country utility function which depends on each of the above mentioned factors. Clearly, however, unless

11 Notice that this coefficient resembles $n$. The implication is that the home and foreign monetary authorities will have equal (for $\gamma=\delta$ ) abilities to influence their respective economies when each have monetary autonomy. 
the home country desires a corner solution in terms of the home monetary authorities influence $\left(\pi_{41}\right)$, a corner solution in terms of importing systematic foreign inflation $\left(\pi_{39}, \pi_{40}\right)$ or a corner solution in terms of the stability of the exchange rate $\left(E_{t}=E_{0}\right)$, the optimal exchange rate policy calls for some degree of intervention. If the home economy desires a corner solution in terms of insulating their economy from the unanticipated foreign money disturbances then clearly the optimal solution is to set $v=b k$. As $v$ diverges upward from bK the home monetary authorities gain stability in the exchange rate but increasingly lose monetary autonomy, home monetary influence, and the home economy becomes increasingly more subject to the potential of importing the systematic inflation of foreigners. For this reason we would expect the optimal value for $\checkmark$ to lie somewhere within the $(0, b k)$ range.

\section{Implications for the Exchange Rate}

In this section we focus on the implications of the model for the exchange rate. Primary attention is given to the determinants of the exchange rate for the general case of a managed float.

As equation (23) indicates, there are three basic sets of factors which determine the exchange rate: (i) the parameters of the model--specifically the target exchange rate $\left(E_{0}\right)$ and the degree of intervention $(v),(i i)$ the systematic home and foreign money and income variables, and (iii) the unanticipated home and foreign money disturbances. Systematic movements in the exchange rate are determined by the systematic money and income variables and also, in particular, by the target exchange rate $\left(E_{0}\right)$ and degree of intervention $(v)$. Deviations from this trend--unanticipated movements in the exchange rate--result 
from unanticipated monetary disturbances, as well as forecasting revisions and random disturbances. 12

Consider first the systematic movements in $E_{t}$. For ease of reference we recall the managed exchange rate equation and present each of the coefficients explicitly. This appears as

$$
\begin{aligned}
E_{t}= & \left(\bar{m}-\bar{k}+\beta+v E_{0}\right) /(1+v)+\frac{1}{b} \sum_{j=1}^{\infty}\left(\frac{b}{T+b+v}\right)^{j} \bar{D}_{t+j-1}^{e}-\frac{a}{b} \sum_{j=1}^{\infty}\left(\frac{b}{1+b+v}\right)^{j} \bar{y}_{t+j-1}^{e} \\
& +\frac{1}{1+a \gamma+b+v} \tilde{D}_{t}-\frac{1+a n(\gamma-\delta)}{1+a \gamma+b+v} \tilde{D}_{t}^{\star}+v_{t, 3}+e_{t, 3}
\end{aligned}
$$

where, once again, $\bar{X}=X-X^{*} ; X=m, k, D$, and $Y$. The thrust of this equation is that relative (home vs. foreign) money $\left(\bar{D}_{t+j}^{e}\right)$ and income $\left(\bar{Y}_{t+j}^{e}\right)$ variables set the trend for the exchange rate. This trend is anchored by the target exchange rate $E_{0}$. Intervention has the effect of weakening the influence of the systematic money and income variables, and strengthening the influence of the target exchange rate. In effect $v$ determines the ease with which $\bar{D}_{t+j}^{e}$ and $\bar{Y}_{t+j}^{e}$ are allowed to drift $E_{t}$ away from $E_{0}$. In the extreme case of flexible exchange rates $(\nu=0)$ the systematic pull of $E_{0}$ is released and the systematic relative money and income are given maximum weight. In the opposite case of fixed exchange rates, the influence of $\bar{D}_{t+j}^{e}$ and $\bar{Y}_{t+j}^{e}$ is prevented. In lieu of influencing $E_{t}$, the systematic money and income variables have full impact on $M_{t}$.

12 Apart from demonstrating the role of systematic and unanticipated monetary policy in determining the exchange rate, the present analys is also emphasizes the importance of announcements. For example, announcements of $D_{t+j}$ or $D_{t+j}^{*}$ which, in general, differ from the past predictions of these variables cause $V_{t}$ as well as movements in $D_{t+j}^{e}$ and $D_{t+j}^{*^{e}}$ which become incorporated into the current $E_{t}$ 
It should also be pointed out that the systematic part of current money and income do not have full impact on the current exchange rate. This result holds even in the extreme case of flexible exchange rates $(v=0)$, as is evident in equation (23) by the coefficient $\left(\frac{1}{1+b}\right)$ on $\delta_{t}^{e}$ and $\left(\frac{a}{T+b}\right)$ on $P_{t}^{e}$. This is because to the extent $\bar{D}_{t}$ and $\nabla_{t}$ were anticipated they were incorporated into $E_{t-1}, E_{t-2}, \ldots$ Likewise, the part of $\bar{D}_{t+j}$ and $P_{t+j}(j=1, \ldots, \infty)$ that is perceived becomes (with declining weights) part of $E_{t}$.

Although it is not immediately apparent from the reduced form $E_{t}$ equation (23), the influence of $\bar{D}_{t+j}^{e}$ and $\bar{\gamma}_{t+j}^{e}$ enters through the forward exchange rate $\left(E_{t+1}^{e}\right)$. The role of the forward exchange rate is introduced via equations (8) through (10). Updating the purchasing power parity equation by one period and taking expectations of both sides conditioned on the information available in time period $t$ gives $P_{t+1}^{e}=E_{t+1}^{e}+P_{t+1}^{*}$, which together with the Fisher relations, (9) and (10), and the assumption of real interest parity (8), implies $i_{t}-i_{t}^{\star}=E_{t+1}^{e}-E_{t}$. The substitution of $E_{t+1}^{e}-E_{t}$ for $i_{t}-i_{t}^{\star}$ simply incorporates the characteristic of the model that the forward premium equals the nominal interest rate differential. The determinants of the forward rate $\left(E_{t+1}^{e}\right)$ are given by updating $E_{t}$ by one period and taking expectations conditioned on the information available in time period t. Following this recursive process introduces the influence of $D_{t+1}^{e}$ and $\vec{\gamma}_{t+j}^{e}$ through their perceived influence on $\bar{P}_{t+j}^{e}$ and thereby onto $E_{t+j}, j=1, \ldots, \infty$. The forward market has the effect of stabilizing the exchange rate since it allocates the determination of $E_{t}$, with declining weights, over the present and the infinite future. It is also clear that a greater interest sensitivity of money demand (b) tends to shift the determination of $E_{t}$ away from current relative money and income and toward the expectations of the future values of those variables. 
We now turn to the unanticipated monetary disturbances. Notice from (23) that a one percentage point unanticipated monetary disturbance implies $a 1 /(1+a y+b+v)$ depreciation in the exchange rate from the standpoint of the expanding currency. An unanticipated foreign monetary disturbance, however, carries with it an additional $a n(\gamma-\delta) /(1+a \gamma+b+\nu)$ depreciation in the foreign currency. 13 This is because $\tilde{D}_{t}^{*}$ affects both $P_{t}$ and $P_{t}^{*}$ through the influence of $r_{t}^{*}$. For $\gamma>\delta$ the effect of $\tilde{D}_{t}^{\star}$ on $P_{t}$ is proportionately less than that on $\mathrm{P}_{\mathrm{t}}^{*}$. Proportionately more of the adjustment of money demand toward money supply is made by the movement in output in the home country, hence the foreign currency depreciates even further.

Another type of unanticipated disturbance which should be investigated concerns devaluations. For this purpose consider the above equations which represent the case of fixed exchanges rates. As the $P_{t}$ equation points out, an unanticipated devaluation in the home currency, represented by raising $E_{t}$ from $E_{0}$ to $E_{1}$, causes an equivalent unanticipated home price increase. This is because $P_{t}^{*}$ is independent of the home country's actions and the condition of purchasing power parity must be maintained. An unanticipated devaluation of the home currency implies a positive current $\tilde{P}_{t}$ hence an effect on $y_{t}$. An unanticipated devaluation also has the effect of increasing the home money stock.

On the other hand, if the monetary authorities of the home country announce in period $t$ that they will devalue in period $t+1$ (and they are believed) an entirely different result follows. The anticipated next period devaluation has no effect on the current home price level since $P_{t}^{*}$ is given exogenously to the

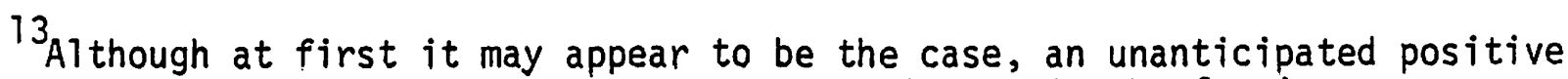
foreign money disturbance cannot cause an appreciation in the foreign currency. Mathematicaliy, lim $\operatorname{an}(\gamma-\delta)=-1$, hence the limiting value of $[1+a n(\gamma-\delta)] /(1+a \gamma+b+v)$ is zero for $\delta, \gamma>0$. 
home country and the authorities are currently maintaining the exchange rate at $E_{0}$. Hence there is no contemporaneous effect on $Y_{t}$.

The anticipated next period devaluation, however, has the effect of decreasing the current money stock of the home country. This implication is not apparent from the reduced form $M_{t}$ equation given above since this expression was derived under the assumption that $E_{t+j}^{e}=E_{0}, j=1, \ldots, \infty$. As we show in the appendix, the reduced form $M_{t}$ equation for a period during which a future (period $t+1$ ) devaluation is announced appears as

$$
M_{t}=\bar{k}+E_{0}+m^{*}+b\left(E_{0}-E_{1}\right)+\frac{\theta}{b}(1-b)\left[D_{t}^{*}-a Y_{t}^{*} e^{e}\right]+a Y_{t}^{e}+\tilde{D}_{t}^{\star}+e_{t, 11}+v_{t, 11} .
$$

This implies that an announced next-period $\left(E_{1}-E_{0}\right)$ devaluation of the home currency causes a $b\left(E_{1}-E_{0}\right)$ current decrease in the money stock of the home currency. The channel whereby the announced devaluation affects the home money stock is, of course, the home nominal interest rate. Since, in general, $i_{t}-i_{t}^{*}=E_{t+1}^{e}-E_{t}$. and $i_{t}^{*}$ is given exogenously to the home country, an announcement of a next-period $\left(E_{1}-E_{0}\right)$ devaluation implies (if fully believed) that $i_{t}$ must currently increase relative to $i_{t}^{*}$ by $E_{t+1}^{e}-E_{t}=E_{1}-E_{0}$. The increase in the home interest rate reduces the home demand for money which requires an equal decrease in the home money stock in order to maintain purchasing power parity at the current exchange rate $E_{0}$.

This also points out that an announcement in period $t$ of a devaluation in period $t+2, t+3, \ldots$, will have no effect in the current period. This is because $E_{t}=E_{t+1}^{e}=E_{0}$, hence $i_{t}$ must equal $i_{t}^{*}$, so that there is no mechanism whereby a forthcoming devaluation can yet affect the home demand for money,

Finally, we should investigate the implications for $M_{t}, P_{t}$, and $Y_{t}$ of a current = devaluation that was not unanticipated but instead was announced in period $t-1$. 
As we have just shown, such an announcement has the effect in period $t-1$ of decreasing $M_{t-1}$ but leaving $P_{t-1}$ and $Y_{t-1}$ unaffected. In period $t$, however, $P_{t}$ must increase proportionately to the increase in $E_{t}$ (from $E_{0}$ to $E_{1}$ ). In addition, with no further anticipated devaluations, $E_{t+1}^{e}$ must equal $E_{t}$ at its new level $\left(E_{p}\right)$. Hence $i_{t}$ must equal $i_{t}^{*}$. This implies that the home price level and money stock. will be at the same levels in period $t$ regardless of whether the devaluation was announced in period $t-1$ or whether it is unanticipated. However, in the case where the devaluation was announced, the current price disturbance is not unanticipated hence there is no effect of the devaluation on $Y_{t}$. In addition, with an announced devaluation the home money stock at first decreases (in the announced period) and then increases rapidly (in the realized period), whereas the home money stock simply increases in the current period when the home currency is unexpectedly devalued.

\section{Conclusion}

In this paper we investigate the determination of output, the price level, and the money stock of a small open economy under various exchange rate regimes. The formal setup centers around a two country world--home and foreign--where the home country is small. and the foreign economy comprises the rest-of-theworld. A key feature of the model is the existence of an aggregate Phillips curve type relationship between employment (output) and unanticipated price disturbances in each of the economies. For the large economy, the implications of this Phillips curve relationship have been examined by Lucas $(1972,1973)$, Barro (1976, 1977), Sargent (1973), Sargent and Wallace (1975), and others. Here, we focus on its implications for the small economy. In particular, primary interest is in delineating the channels of home and foreign monetary influence, and in discriminating between the effects of home-generated and 
foreign-generated unanticipated monetary disturbances. As such, the model has important implications for monetary autonomy and for the international transmission of disturbances under the alternative regimes of a fixed, managed, and flexible exchange rate. We are also able to identify the factors which determine the exchange rate and provide some insight into the optimal degree of intervention. We will conclude by summarizing some of the main results.

The first of these is that unanticipated foreign monetary disturbances can be transmitted to the home country more heavily under flexible exchange rates than under fixed rates. This follows from the existence of a foreign and home Phillips curve and a global aggregate expenditure (IS) curve. Together these imply that unanticipated foreign monetary disturbances cause both reserve flows and movements in the real part of the rate of interest. The reserve flows dominate under fixed exchange rates and the interest rate effect dominates under flexible rates. For a sufficiently steep aggregate expenditure curve and a sufficiently responsive foreign Phillips curve the real interest rate effect under flexible exchange rates can exceed that of the money movements under fixed rates so that foreign disturbances are transmitted more heavily under flexible rates than under fixed rates.

A second important result to note here is that these effects are of opposite sign. An unanticipated foreign money expansion generates a positive unanticipated home price disturbance to the extent the money supply of the home country is increased, but an opposite unanticipated price disturbance to the extent the real interest rate is decreased. The implication is that a dirty (?) float is the only exchange rate regime which allows a country to insulate itself from the unanticipated foreign monetary disturbances. Although this permits the home monetary authorities their desired monetary autonomy, it simultaneously reduces 
their ability to influence the home economy and opens the home economy to the import of systematic foreign inflation.

In general, the factors determining the exchange rate are (i) the parameters of the system--in particular, the target exchange rate and degree of intervention, (ii) the systematic relative (domestic vs. foreign) money and income variables, and ( $i i i)$ the unanticipated money disturbances. The systematic part of the current home money variable has a larger impact on the exchange rate than the unanticipated part since an unanticipated money disturbance carries with it an output response which partially offsets the effect on home prices. A similar result holds for systematic and unanticipated foreign monetary disturbances; however, unanticipated foreign monetary disturbances have an additional impact which depends on the comparative slopes of the home and foreign Phillips curves.

Finally, an analysis of devaluation in this framework indicates that an unanticipated devaluation of the home currency causes an unanticipated home price increase, an increase in home output, and an increase in the home money stock. An announced next-period devaluation, on the other hand, has the effect of decreasing the home money stock in the announced period and increasing rapidiy the home money stock in the following period. No output effects are implied, however. The mechanism whereby the announced devaluation effects the home economy is the capital market. The announced devaluation implies a forward home currency premium which forces an increase in the home nominal interest rate currently in order to maintain interest parity. This also implies that an announcement in period $t$ of a devaluation in period $t+2, t+3$, etc. will have no effect in the current period since there is no mechanism whereby a forthcoming devaluation can yet affect the home demand for money. 


\section{APPENDIX}

In the appendix we derive the results cited in the text.

The results for the foreign economy will be derived first. It is convenient here to define $x^{e(t)}$ as the rational expectation of $x$, formed in period $t$, and $x^{e(t-1)}$ as the rational expectation of $x$, formed in period $t-1$. That is,

$$
\begin{aligned}
& x_{t}^{e(t-1)} \equiv E\left[X_{t} \mid I_{t-1}\right], \text { and } \\
& x_{t+j}^{e(t)} \equiv E\left[X_{t+j} \mid I_{t}\right], \quad j=1, \ldots, \infty
\end{aligned}
$$

where $I_{t}$ is information available in period $t$.

It will later become convenient to use the shorthand version of these given in equations (12) and (13) of the text.

Since the contribution of the home country's demand for and supply of goods and bonds is assumed to be insignificant vis-a-vis the foreign economy, $M_{t}^{*}, P_{t}^{*}$, $Y_{t}^{*}$, and $i_{t}^{*}$ are determined by equations (3), (4), (6), (10), and (11). Substituting $(3),(6)$, and (10) into (4) using (11), and defining $\theta=\frac{b}{1+b}$ gives

$$
P_{t}^{*}=\frac{\theta}{b} M_{t}^{*}-\frac{\theta}{b} k^{*}-\frac{a \theta}{b} Y_{t}^{*} e^{(t-1)}-\frac{(a \delta+b k) \theta}{b} \tilde{p}_{t}^{*}+\theta r_{n}^{*}+\theta P_{t+1}^{*} e^{(t)}+\theta \tau_{t}^{*}-\frac{a \theta}{b} \varepsilon_{t}^{*}-\frac{\theta}{b} \varepsilon_{t}^{*}
$$

Updating ( $1 \mathrm{~A}$ ) by $\mathrm{j}$ periods and taking expectations conditioned on the information available in period $t$ gives

$$
P_{t+j}^{*} e^{(t)}=\frac{\theta}{b} M_{t+j}^{*} e^{(t)}-\frac{\theta^{*}}{b^{*}}-\frac{a \theta^{*}}{b} Y_{t+j}^{*} e^{(t)}+\theta r_{n}^{*}+\theta P_{t+j+1}^{*^{e(t)}},
$$

since $\tilde{P}_{t+j}^{\star} e(t), \tau_{t+j}^{\star} e(t)$, and $\epsilon_{t+j}^{\star} e(t)$ are all zero, $j=1, \ldots, \infty$. Substituting this relation into equation $(1 A)$ for $j=1, j=2$, and continuing in a recursive fashion, gives 


$$
\begin{aligned}
& P_{t}^{*}=\frac{\theta}{b} H_{t}^{*}-\frac{a \theta^{*}}{b} Y_{t}^{*} e(t-1)+\frac{1}{b} \sum_{j=1}^{\infty} \theta^{j+1} M_{t+j}^{*} e(t)-\frac{a}{b} \sum_{j=1}^{\infty} \theta^{j+1} Y_{t+j}^{*} e(t)-k^{*}+b r_{n}^{*} \\
& -\frac{(a \delta+b k) \theta_{\tilde{P}_{t}^{*}}}{b}+\theta \tau_{t}^{\star}-\frac{a \theta^{\epsilon}}{b}-\frac{\theta}{b^{\epsilon}}{ }_{t}^{*}
\end{aligned}
$$

$$
\text { since } \sum_{j=1}^{\infty} \theta^{j}=b \text {. }
$$

Now by definition $\tilde{P}_{t}^{\star}=P_{t}^{*}-P_{t}^{*} e(t-1)$. Taking expectations of both sides of equation ( $3 A$ ) conditioned on the information available in time period $(t-1)$ gives

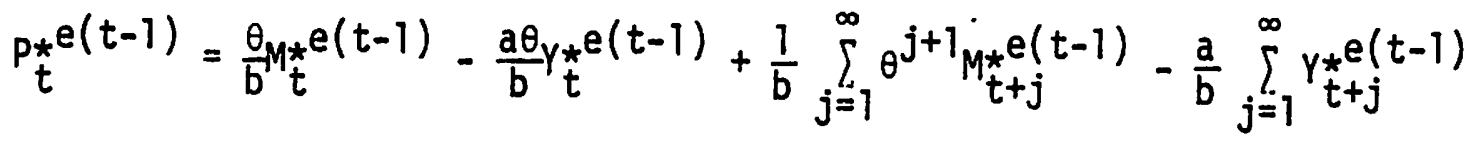

$$
\begin{aligned}
& -k^{\star}+b r_{n}^{\star}
\end{aligned}
$$

since $\tilde{P}_{t}^{\star} e^{(t-1)}, \tau_{t}^{\star^{e}(t-1)}$, and $\epsilon_{t}^{\star^{e}(t-1)}$ are all zero. Subtracting $P_{t}^{\star^{e}(t-1)}$ as given in $(4 A)$, from $P_{t}^{*}$ as given in $(3 A)$, and solving for $\tilde{P}_{t}^{\star}$ gives

$$
\tilde{P}_{t}^{\star}=n \tilde{M}_{t}^{\star}+\frac{n}{\theta} \sum_{j=1}^{\infty} \theta^{j+1} v_{t+j}^{D^{*}}-\frac{a \eta}{\theta} \sum_{j=1}^{\infty} \theta^{j+1} v_{t+j}^{Y *}+n b \tau_{t}^{*}-a n \epsilon_{t}^{\star}-n \varepsilon_{t}^{\star}
$$

where $v_{t+j}^{D^{*}}=v_{t+j}^{M^{*}}=M_{t+j}^{*} e(t)-M_{t+j}^{*} e(t-1)$ and $v_{t+j}^{Y^{*}} \equiv Y_{t+j}^{*} e(t)-Y_{t+j}^{*} e(t-1), j=1, \ldots, \infty$. Hence $v_{t+j}^{X}$ constitutes a revision in the period $t-1$ forecast of a variable $x$, made in period $t$. The expression for $\eta$ is that given in the text and corresponds to the coefficient $\pi_{4}$. We have also made use of the unanticipated money definition, $\tilde{M}_{t}^{\star} \equiv M_{t}^{*}-M_{t}^{*} e(t-1)$

Substituting the expression for $\tilde{P}_{t}$ from $(5 A)$ into $(3 A)$ gives 


$$
\begin{aligned}
P_{t}^{*}=\frac{\theta}{b} M_{t}^{*} e(t-1) & +\frac{1}{b} \sum_{j=1}^{\infty} \theta^{j+1} M_{t+j}^{*} e(t)-\frac{a \theta}{b} Y_{t}^{*} e^{e(t-1)}-\frac{a}{b} \sum_{j=1}^{\infty} \theta^{j+1} Y_{t+j}^{*} e^{(t)} \\
& -k^{*}+b r_{n}^{*}+n \tilde{M}_{t}^{*}-n \frac{a \delta+b k}{b} \sum_{j=1}^{\infty} \theta^{j+1}\left[v_{t+j}^{D^{*}}-a v_{t+j}^{Y *}\right] \\
& +n\left[b \tau_{t}^{*}-a \epsilon_{t}-\varepsilon_{t}^{*}\right] .
\end{aligned}
$$

In the text we make use of the relation $M_{t}^{*}=m^{*}+D_{t}^{*}$. It also is convenient to define $x_{t}^{e}$ and $x_{t+j}^{e}$ as in equations (13) and (14). With this shorthand, (6A) may be rewritten as

$$
P_{t}^{*}=\pi_{1}+\pi_{2} \sum_{j=1}^{\infty} \theta_{t+j-1}^{j}-\pi_{3} \sum_{j=1}^{\infty} \theta^{j} Y_{t+j-1}^{\psi_{t}^{*}}{ }_{t+\pi_{4}}^{e} \tilde{D}_{t}^{*}+V_{t}^{*}+e_{t}^{*}
$$

$$
\text { where } \begin{aligned}
\pi_{1} & =b r_{n}^{*}+m^{*}-k^{*}, \\
\pi_{2} & =1 / b, \\
\pi_{3} & =a / b, \\
\pi_{4} & =n=1 /(1+a \delta+b(k+1)), \\
v_{t}^{*} & =-n \frac{a \delta+b k}{b} \sum_{j=1}^{\infty} \theta^{j+1}\left[v_{t+j}^{D^{*}}-a v_{t+j}^{\gamma *}\right], \text { and } \\
e_{t}^{*} & =n\left[b \tau_{t}^{*}-a \epsilon_{t}^{*}-\varepsilon_{t}^{*}\right] .
\end{aligned}
$$

This is the expression given in the text as equation (18).

We now turn to the results for the home country. These results will be derived for the general case of the managed float; that is, a positive finite $v$. The derivation of $P_{t}, M_{t}, E_{t}$, and $Y_{t}$ is a simultaneous equations exercise. We begin by determining $E_{t}$. 
Substituting into equation (2) from equation (1), (5), and (17), and using (14) gives

$$
P_{t}=\lambda+D_{t}^{e(t-1)}+\tilde{D}_{t}-v E_{t}-k-a Y_{t}^{e(t-1)}-a \gamma \widetilde{P}_{t}-a \epsilon_{t}+b i_{t}-\varepsilon_{t}
$$

where $\lambda=m+\beta+\nu E_{0}$. Similarly substituting into (4) from (3), (6), and (15), and using $D_{t}^{*}=H_{t}^{*}$ gives

$$
P_{t}^{*}=m^{*}+D_{t}^{*} e(t-1)+\tilde{D}_{t}^{*}-k^{*}-a \gamma_{t}^{\star} e^{e(t-1)}-a \delta_{t}^{*}-a \epsilon_{t}^{*}+b i_{t}^{\star}-\varepsilon_{t}^{*}
$$

Subtracting $P_{t}^{*}$ from $P_{t}$ and noting that $\tilde{P}_{t}=\tilde{E}_{t}+\tilde{P}_{t}^{\star}$ by $(7)$ and $(14)$, gives

$$
\begin{aligned}
E_{t}(1+b+v)= & \left(\lambda-m^{*}-k+k^{*}\right)+D_{t}^{e(t-1)}-D_{t}^{*} e(t-1)-a \gamma_{t}^{e(t-1)}+a \gamma_{t}^{*} e(t-1) \\
& +a(\delta-\gamma) \tilde{P}_{t}^{\star}+\tilde{D}_{t}-\tilde{D}_{t}^{\star}-\alpha \gamma \tilde{E}_{t}+b E_{t+1}^{e(t)}-a\left(\epsilon_{t}^{\left.-\epsilon_{t}^{*}\right)}-\left(\varepsilon_{t}-\varepsilon_{t}^{\star}\right) .\right.
\end{aligned}
$$

Here we have made use of equation (8) and the relation $P_{t+1}^{e(t)}=E_{t+1}^{e(t)}+P_{t+1}^{P_{t}} e^{(t)}$, which together imply that $i_{t}-i_{t}^{\star}=E_{t+1}^{e}-E_{t}$.

Define $\omega \equiv \frac{b}{1+b+v}$, multiply both sides of equation (10A) by $\frac{\omega}{b}$, update $E_{t}$ by $j$ periods $(j=1, \ldots, \infty)$, and take expectations of $E_{t+j}$ conditioned on the information available in time period $t$. The recursive substitution of $E_{t+j}$ into (10A) gives

$$
\begin{aligned}
& E_{t}=\left(\lambda-m^{*} k+k^{*}\right) /(1+v)+\frac{\omega_{b}}{b} C_{t}^{e(t-1)}-\frac{\omega_{b} D_{t}^{*}}{b(t-1)}-\frac{a \omega_{Y}}{b} Y_{t}^{e(t-1)}+\frac{a \omega^{*}}{b} \gamma_{t}^{*} e^{(t-1)} \\
& +\frac{a \omega}{b}(\delta-\gamma) \tilde{P}_{t}^{*}+\frac{\omega}{b} \widetilde{D}_{t}-\frac{\omega}{b} \tilde{D}_{t}^{*}-\frac{a \gamma \omega \tilde{E}_{t}}{b}+\frac{1}{b} \cdot \sum_{j=1}^{\infty} \omega^{j+1} D_{t+j}^{e(t)}-\frac{1}{b} \sum_{j=1}^{\infty} \omega^{j+1} D_{t+j}^{*} e^{e(t)} \\
& -\frac{a}{b} \sum_{j=1}^{\infty} \omega^{j+1} Y_{t+j}^{e(t)}+\frac{a}{b} \sum_{j=1}^{\infty} \omega^{j+1}{ }^{*} e_{t+j}^{(t)}-\frac{a \omega}{b}\left(\epsilon_{t}-\epsilon_{t}^{\star}\right)-\frac{\omega}{b}\left(\varepsilon_{t}-\varepsilon_{t}^{\star}\right) \text {. }
\end{aligned}
$$


Now, since by definition $\tilde{E}_{t} \equiv E_{t}-E_{t}^{e(t-1)}$ we must now determine $E_{t}^{e(t-1)}$. Taking expectations of both sides of equation (11A) conditioned on the information available at time period $t-1$ gives

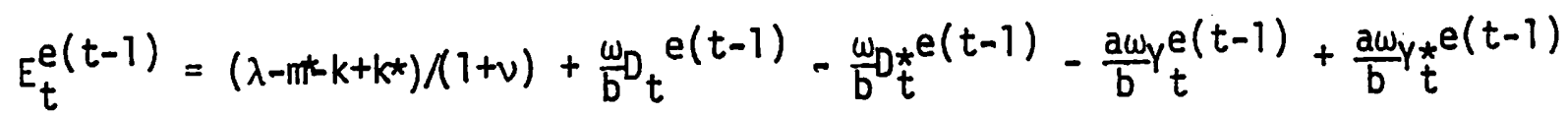

$$
\begin{aligned}
& +\frac{1}{b} \sum_{j=1}^{\infty} \omega^{j+1} D_{t+j}^{e(t-1)}-\frac{1}{b} \sum_{j=1}^{\infty} \omega^{j+1} D_{t+j}^{*} e(t-1)-\frac{a}{b} \sum_{j=1}^{\infty} \omega^{j+1} Y_{t+1}^{e(t-1)} \\
& +\frac{a}{b} \sum_{j=1}^{\infty} \omega^{j+1} Y_{t+j}^{* e(t-1)}
\end{aligned}
$$

Subtracting $E_{t}^{e(t-1)}$, as given in $(12 A)$, from $E_{t}$, as given in $(11 A)$, and defining $\alpha=1 /(1+a \gamma+b+\nu)$ gives

$$
\begin{aligned}
\tilde{E}_{t}=\alpha \tilde{D}_{t} & -\alpha \tilde{D}_{t}^{*}+\alpha \alpha(\delta-\gamma) \tilde{P}_{t}^{*}+\alpha \sum_{j=1}^{\infty} \omega^{j}\left[v_{t+j}^{D}-v_{t+j}^{D *}-a v_{t+j}^{Y}+a v_{t+j}^{Y *}\right] \\
& -\alpha \alpha\left(\epsilon_{t}-\epsilon \epsilon_{t}^{*}\right)-\alpha\left(\varepsilon_{t}-\varepsilon_{t}^{\star}\right)
\end{aligned}
$$

where the $v_{t+j}^{X}$, once again, represent revisions in expectations of the respective $X^{\prime} s ; X=D, D^{*}, Y, Y^{*}$.

Substituting this expression into (11A) gives

$$
\begin{aligned}
& E_{t}=\left(\lambda-m^{*}-k+k^{*}\right) /(1+\nu)+\frac{\omega_{0}}{b} D_{t}^{e(t-1)}-\frac{\omega_{0}}{b} D_{t}^{*} e^{(t-1)}-\frac{a \omega_{Y}}{b} e_{t}^{(t-1)}+\frac{a \omega_{Y}}{b} Y_{t}^{e(t-1)} \\
& +\frac{1}{b} \sum_{j=1}^{\infty} \omega^{j+1} D_{t+j}^{e(t)}-\frac{1}{b} \sum_{j=1}^{\infty} \omega^{j+1} D_{t+j}^{\star} e^{e(t)}-\frac{a}{b} \sum_{j=1}^{\infty} \omega^{j+1} Y_{t+j}^{e(t)}+\frac{a}{b} \sum_{j=1}^{\infty} \omega^{j+1} Y_{t+j}^{*} e^{e(t)} \\
& +a \alpha(\delta-\gamma) \tilde{P}_{t}^{\star}+\alpha \tilde{D}_{t}-\alpha \tilde{D}_{t}^{\star}+\left(\alpha-\frac{\omega}{b}\right) \sum_{j=1}^{\infty} \omega^{j}\left[v_{t+j}^{D}-v_{t+j}^{D^{*}}-a v_{t+j}^{Y}+a v_{t+j}^{y^{*}}\right] \\
& -a \alpha\left(\epsilon_{t}-\epsilon_{t}^{*}\right)-\alpha\left(\varepsilon_{t}-\varepsilon_{t}^{*}\right)
\end{aligned}
$$


Substituting into (14A) for $\tilde{P}_{t}^{\star}$ from equation (19) then gives

$$
\begin{aligned}
E_{t}= & \left(\lambda-m^{*}-k+k^{*}\right) /(1+v)+\frac{1}{b} \sum_{j=1}^{\infty} \omega^{j} D_{t+j-1}^{e}-\frac{1}{b} \sum_{j=1}^{\infty} \omega^{j} D_{t+j-1}^{*}-\frac{a}{b} \sum_{j=1}^{\infty} \omega^{j} Y_{t+j-1}^{e} \\
& +\frac{a}{b} \sum_{j=1}^{\infty} \omega^{j} Y_{t+j-1} e^{e}+\alpha \tilde{D}_{t}-\alpha[1+a(\gamma-\delta) n] \tilde{D}_{t}^{*}+a \alpha(\delta-\gamma) v_{t}^{*} \\
& +\left(\alpha-\frac{\omega}{b}\right) \sum_{j=1}^{\infty} \omega^{j}\left[v_{t+j}^{D}-v_{t+j}^{D^{*}}-a v_{t+j}^{Y}+a v_{t+j}^{Y *}\right]+a \alpha(\delta-\gamma) e_{t}^{*}-a \alpha\left(\epsilon_{t}-\epsilon_{t}^{*}\right) \\
& -\alpha\left(\varepsilon_{t}-\varepsilon_{t}^{*}\right) .
\end{aligned}
$$

Here we have made use of the shorthand definitions of $x_{t}^{e(t-1)}$ and $x_{t+j}^{e(t)}$. Substituting into (15A) for $\lambda=m+\beta+\nu E_{0}$ and using the definition $\bar{X}=X-X * ; X=D, Y$, gives

$$
E_{t}=\pi_{17}+\pi_{18} \sum_{j=1}^{\infty} \omega^{j} \tilde{D}_{t+j-1}^{e}-\pi_{19} \sum_{j=1}^{\infty} \omega^{j} p_{t+j-1}^{e}+\pi_{20} \tilde{D}_{t}-\pi_{21} \tilde{D}_{t}^{\star}+v_{t, 3}+e_{t, 3}
$$

$$
\text { where } \begin{aligned}
\pi_{17} & =\left(m-m^{*}-k+k^{*}+\beta+v E_{0}\right) /(1+v), \\
\pi_{18} & =1 / b, \\
\pi_{19} & =a / b, \\
\pi_{20} & =1 /(1+a \gamma+b+v), \\
\pi_{21} & =[1+a n(\gamma-\delta)] /(1+a \gamma+b+v), \\
v_{t, 3} & =a \alpha(\delta-\gamma) v_{t}^{*}+\left(\alpha-\frac{\omega}{b}\right) \sum_{j=1}^{\infty} \omega^{j}\left[v_{t+j}^{D}-v_{t+j}^{D^{*}}-a v_{t+j}^{\gamma}+a v_{t+j}^{\gamma *}\right], \text { and } \\
e_{t, 3} & =a \alpha(\delta-\gamma) e_{t}^{\star}-a \alpha\left(\epsilon_{t}-\epsilon_{t}^{*}\right)-\alpha\left(\varepsilon_{t}-\varepsilon_{t}^{\star}\right) .
\end{aligned}
$$

This is the expression given in the text as equation (23).

The home price level may then be determined by adding $P_{t}^{*}$ from equation (7A) to $E_{t}$ from $(16 \mathrm{~A})$. The result is 


$$
\begin{aligned}
P_{t}= & \pi_{6}+\pi_{7} \sum_{j=1}^{\infty} \omega^{j} D_{t+j-1}^{e}-\pi_{8} \sum_{j=1}^{\infty} \omega^{j} Y_{t+j-1}^{e}+\pi_{9} \sum_{j=1}^{\infty}\left(\theta^{j}-\omega^{j}\right) D_{t+j-1}^{\star e} \\
& -\pi_{10} \sum_{j=1}^{\infty}\left(\theta^{j}-\omega^{j}\right) Y_{t+j-1}^{\star e}+\pi_{11} \tilde{D}_{t}+\pi_{12} \tilde{D}_{t}^{\star}+V_{t, 1}+e_{t, 1}
\end{aligned}
$$

$$
\text { where } \begin{aligned}
\pi_{6} & =b r_{n}^{*}+\left[m+v m^{*}-k-v k^{*}+v E_{0}+\beta\right] /(1+v), \\
\pi_{7} & =1 / b \\
\pi_{8} & =a / b \\
\pi_{9} & =1 / b \\
\pi_{10} & =a / b \\
\pi_{11} & =1 /(1+a \gamma+b+v) \\
\pi_{12} & =n(v-b k) /(1+a \gamma+b+v) \\
v_{t, 1} & =v_{t}^{*}+v_{t, 3}, \text { and } \\
e_{t, 1} & =e_{t}^{*}+e_{t, 3} .
\end{aligned}
$$

This is the expression given in the text, equation (20).

Taking expectations of both sides of equation (17A) conditioned on the information available in time period $(t-1)$, and subtracting this result from (17A) gives the expression for $\tilde{P}_{t}$. The result is

$$
\widetilde{P}_{t}=\pi_{11} \tilde{D}_{t}+\pi_{12} \tilde{D}_{t}^{*}+v_{t, 1}+e_{t, 1}
$$

This is equation (21) given in the text.

The reduced form expression (22) for $Y_{t}$ may be obtained by substituting into equation (5) for $\widetilde{P}_{t}$ from (18A). This gives 


$$
Y_{t}=Y_{t}^{e}+\pi_{15} \tilde{D}_{t}+\pi_{16} \tilde{D}_{t}^{*}+v_{t, 2}+e_{t, 2}
$$

where $\pi_{15}=\gamma /(1+a \gamma+b+v)$,

$$
\begin{aligned}
\pi_{16} & =m(v-b k) /(1+a \gamma+b+v), \\
v_{t, 2} & =\gamma v_{t, 1}, \text { and } \\
e_{t, 2} & =\gamma e_{t, 1}+\epsilon_{t} .
\end{aligned}
$$

Finally, $M_{t}$ may be determined by substituting into equation (17) for $E_{t}$ from equation (16A). This gives

$$
\begin{aligned}
M_{t}= & m+\beta+v E_{0}+D_{t}^{e}+\tilde{D}_{t}-\frac{v}{1+v^{L}}\left[m-m^{*}-k+k^{*}+\beta+v E_{0}\right] \\
& -\frac{v}{b} \sum_{j=1}^{\infty} \omega^{j} D_{t+j-1}^{e}+\frac{a v}{b} \sum_{j=1}^{\infty} \omega^{j} \bar{Y}_{t+j-1}^{e}-\frac{v}{1+a \gamma^{2}+b+v} \tilde{D}_{t} \\
& +\frac{v(1+a n(\gamma-\delta))}{1+a \gamma+b+v} \tilde{D}_{t}^{*}-v v_{t, 3}-v e_{t, 3},
\end{aligned}
$$

which simplifies to

$$
\begin{aligned}
M_{t}= & \pi_{22}+\pi_{23} D_{t}^{e}+\pi_{24} D_{t}^{\star^{e}}+\pi_{25} \sum_{j=2}^{\infty} \omega^{j} \widetilde{D}_{t+j-1}^{e}-\pi_{26} \sum_{j=1}^{\infty} \omega^{j} \gamma_{t+j-1}^{e} \\
& +\pi_{27} \tilde{D}_{t}+\pi_{28} \tilde{D}_{t}^{\star}+v_{t, 4}+e_{t, 4}
\end{aligned}
$$

where $\pi_{22}=\left[v m^{*}+m+v E_{0}-v k^{*}+v k+\beta\right] /(1+v)$,

$$
\begin{aligned}
& \pi_{23}=1-v \omega / b, \\
& \pi_{24}=v \omega / b, \\
& \pi_{25}=v / b,
\end{aligned}
$$




$$
\begin{aligned}
\pi_{26} & =a v / b, \\
\pi_{27} & =(1+a \gamma+b) /(1+a \gamma+b+v), \\
\pi_{28} & =v(1+a n(\gamma-\delta)) /(1+a \gamma+b+v), \\
v_{t, 4} & =v v_{t, 3}, \text { and } \\
e_{t, 4} & =v e_{t, 3} .
\end{aligned}
$$

The fixed exchange rate form of the $P_{t}, E_{t}, Y_{t}$, and $M_{t}$ equations may be inferred by allowing $v \rightarrow \infty$. Similarly for flexible exchange rates, set $v=0$. These coefficients are given in the text.

The revision terms $v_{t, 5}, v_{t, 6}$, and $v_{t, 7}$, and the random error terms $e_{t, 5}$, $e_{t, 6}$, and $e_{t, 7}$ may be inferred by letting $\nu+\infty$ in $v_{t, 1}, v_{t, 2}, v_{t, 4}, e_{t, 1}, e_{t, 2}$, and $e_{t, 4}$, respectively. Likewise $v_{t, 8}, v_{t, 9}, v_{t, 10}, e_{t, 8}, e_{t, 9}$, and $e_{t, 10}$ may be inferred by setting $v=0$ in $v_{t, 1}, v_{t, 2}, v_{t, 4}, e_{t, 1}, e_{t, 2}$, and $e_{t, 4}$, respectively. We leave this exercise to the reader.

Finally, for the case of devaluation, substitute into the home country money demand equation ( 7 ) from equations (5), (7), and (9), and use (8). Substituting the result into the home monetary equilibrium condition (2), gives

$$
\begin{aligned}
M_{t}= & k+P_{t}^{*}-b\left(P_{t+1}^{*}-P_{t}^{*}\right)+E_{0}+b\left(E_{1}-E_{0}\right)+a Y_{t}^{e}-b r_{n}^{*} \\
& +(a \gamma+b k) \tilde{P}_{t}^{*}-b \tau_{t}+\varepsilon_{t}+a \varepsilon_{t}
\end{aligned}
$$

Updating $P_{t}^{*}$ by one period, taking expectations of $P_{t+1}^{*}$ conditioned on the information available in time period $t$ and subtracting $P_{t}^{*}$ from $P_{t+1}^{*}$ gives

$$
P_{t+1}^{* e}-P_{t}^{*}=\frac{\theta}{b} D_{t}^{*} e^{e}-\frac{a \theta}{b} Y_{t}^{*} e^{e}+\frac{\theta}{b^{2}} \sum_{j=1}^{\infty} \theta^{j} D_{t+j}^{* e}-\frac{a \theta}{b^{2}} \sum_{j=1}^{\infty} Y_{t+j}^{*}-n \tilde{D}_{t}^{*}-V_{t}^{*}=e_{t}^{*}
$$


Substituting this expression, together with the expression for $P_{t}^{*}$ and $\tilde{P}_{t}^{*}$ into (22A) and collecting terms gives

$$
M_{t}=\bar{k}+E_{0}+m^{*}+B\left(E_{0}-E_{1}\right)+\frac{\theta}{b}(1-b)\left[D_{t}^{* e}-a Y_{t}^{*}\right]+a Y_{t}^{e}+\widetilde{D}_{t}^{*}+e_{t, 11}+v_{t, 11}
$$

where $v_{t, 11}=v_{t}^{*} / n$, and

$$
e_{t, 11}=e_{t}^{\star} / \eta+a \varepsilon_{t}-b \tau_{t}+\varepsilon_{t} \text {. }
$$

This is the expression given in the text as equation (25). 


\section{REFERENCES}

M. J. Bailey, "The Welfare Cost of Inflationary Finance," J. Polit. Econ., Aprit 1956, 64, 93-110.

R. J. Barro, "Inflation, the Payments Period, and the Demand for Money," J. Folit. Econ., November/December 1970, 78, 1228-63.

, "Rational Expectations and the Role of Monetary Policy," J. Monetary Econ., January 1976, 1-32.

, "A Simple Flexible Exchange Rate Model With Uncertainty and Rational Expectations," Manuscript, University of Rochester, 1977.

and H. Grossman, Money, Employment, and Inflation, Cambridge 1976. and N. Saidi, "Unanticipated Money, Output, and Employment in Canada," Working Paper, University of Rochester and University of Chicago, 1978.

J. F. 0. Bilson, "Rational Expectations and the Exchange Rate," Manuscript, Northwestern University and The International Monetary Fund, 1977.

, "The Monetary Approach to the Exchange Rate: Some Empirical Evidence," Forthcoming, Int. Monetary Fund Staff Papers, 1978.

M. I. Blejer, "The Short-Run Dynamics of Prices and the Balance of Payments," Amer. Econ. Rev., June 1977, 419-28.

G. H. Borts and J. A. Hanson, "The Monetary Approach to the Balance of Payments," Unpublished manuscript, Brown University, 1975.

P. Cagan, "The Monetary Dynamics of Hyperinflation," in M. Friedman, ed., Studies in the Quantity Theory of Money, Chicago 1956.

G. Calvo and C. A. Rodriguez, "A Model of Exchange Rate Determination Under Currency Substitution and Rational Expectations," J. Polit. Econ., June 1977, 117-26.

R. Clower, "The Keynesian Counterrevolution: A Theoretical Appraisal," in Hahn and Brechling, The Theory of Interest Rates, New York 1965.

W. M. Cox, "An Incomplete Information Model of the Monetary Approach to the Balance of Payments," Manuscript, University of Rochester, 1978.

and D. S. Wilford, "The Monetary Approach to the Balance of Payments and World Monetary Equilibrium," Manuscript, University of Rochester and The Federal Reserve Bank of New York, January 1978.

J. Frenkel and H. G. Johnson, The Monetary Approach to the BaZance of Payments, London 1976.

M. Friedman, "The Role of Monetary Policy," Amer. Econ. Rev., March 1968, 1-17.

H. Johnson, Essays in Monetary Economics, Cambridge, 1973.

D. T. King, "Monetary Autonomy and Phillips Curve Stability Under Fixed Exchange Rates," Unpublished manuscript, Federal Reserve Bank of New York, 1977. 
R. Lucas, "Expectations and the Neutrality of Money," J. Econ. Theory, April 1972, 103-24.

, "Some International Evidence on Output-Inflation Tradeoffs," Amer. Econ. Rev., June 1973, 326-34.

S. Magee, "Empirical Evidence on the Monetary Approach to the Balance of Payments and Exchange Rates," Amer. Econ. Rev., May 1976, 163-70.

D. T. Mortensen, "A Theory of Wage and Employment Dynamics," in Edmund S. Pheips, et al., Microeconomic Foundations of Employment and Inflation Theory, New York $1970,167-211$.

R. A. Munde11, International Economics, New York 1968.

L. H. Officer, "The Purchasing-Power-Parity Theory of Exchange Rates: A Review Article," Int. Monetary Fund Staff Papers, March 1976, 1-60.

M. G. Porter and P. J. Kouri, "International Capital Flows and Portfolio Equilibrium," J. Polit. Econ., August 1974, 82 .

B. Putnam and D. S. Wilford, "Money, Income, and Causality in the U.S. and the U.K.: A Theoretical Explanation of Different Findings," Amer. Econ. Rev., June 1978.

M. Rothschild, "Models of Market Organization with Imperfect Information: A Survey," J. Polit. Econ., November 1973, 1283-1308.

N. Saidi, "Rational Expectations and the International Transmission of Disturbances Under Flexible Exchange Rates," Working Paper, University of Chicago, 1977.

T. Sargent, "Rational Expectations, the Real Rate of Interest and the Natural Rate of Unemployment," Brookings Papers on Econ. Activity, 1973, 2. and N. Wallace, "Rational Expectations and the Dynamics of Hyperinflation, Inter. Econ. Rev., June 1973, 328-50.

and , "Rational Expectations, the Optimal Monetary Instrument, and the Optimal Money Supply Rule," J. Polit. Econ., April 1975, 241-54.

A. K. Swoboda, "Monetary Policy Under Fixed Exchange Rates: Effectiveness, the Speed of Adjustment and Proper Use," Economica, May 1973, 136-54. 